\title{
Structural and functional adaptation of the lingual papillae of the Egyptian fruit bat (Rousettus aegyptiacus): specific adaptive feeding strategies
}

\author{
R.M. Kandyel ${ }^{1}$, M.M.A. Abumandour² ${ }^{2}$, S.F. Mahmoud ${ }^{3}$, M. Shukry ${ }^{4}$, N. Madkour², \\ A. El-Mansi' ${ }^{5}$, F.A. Farrag 7 \\ ${ }^{1}$ Department of Zoology, Faculty of Science, Tanta University, Tanta, Egypt \\ ${ }^{2}$ Department of Anatomy and Embryology, Faculty of Veterinary Medicine, Alexandria University, Alexandria, Egypt \\ ${ }^{3}$ Department of Biotechnology, College of Science, Taif University, Taif, Saudi Arabia \\ ${ }^{4}$ Department of Physiology, Faculty of Veterinary Medicine, Kafrelsheikh University, Kafrelsheikh, Egypt \\ ${ }^{5}$ Department of Biology, Faculty of Science, King Khalid University, Abha, Saudi Arabia \\ ${ }^{6}$ Department of Zoology, Faculty of Science, Mansoura University, Mansoura, Egypt \\ 'Department of Anatomy and Embryology, Faculty of Veterinary Medicine, Kafrelsheikh University, Kafrelsheikh, Egypt
}

[Received: 19 February 2021; Accepted: 28 March 2021; Early publication date: 28 April 2021]

Background: The current investigation was aimed to clarify the correlations between the feeding strategy and lingual structure of the Egyptian fruit bat captured from the Egyptian east desert.

Materials and methods: The current work was performed on 12 adult Egyptian fruit bats that were observed grossly and with the help of the stereo, light, and scanning electron microscope. There were three types of the lingual papillae: one mechanical (filiform) and two gustatory (fungiform and circumvallate).

Results: There were seven subtypes of filiform papillae recognised on the seven lingual regions. There were few fungiform papillae distributed among the filiform papillae on the lingual tip and two lateral parts of apex and body while fungiform papillae were completely absent in the median part. There were three circumvallate papillae. The central bulb of circumvallate papillae was surrounded by one layer of two segmented circular pad. The lingual tip had cornflower-like and diamond-shaped filiform papillae.

Conclusions: Histochemical results revealed that the lingual glands showed a stronger Alcian Blue (AB)-positive reaction and gave dark blue colour, while the reaction for the periodic acid-Schiff (PAS)-stain was negative. Also, the glands exhibited a blue colour as an indication of positive $A B$ reactivity with combined AB-PAS staining. (Folia Morphol 2022; 81, 2: 400-411)

Key words: Egyptian fruit bat, lingual papillae, scanning electron microscope (SEM), histology, histochemical examination

Address for correspondence: M.M.A. Abumandour, Ass. Prof., Department of Anatomy and Embryology, Faculty of Veterinary Medicine, Alexandria, Egypt, Post Box: 22785, tel: +20 1000322937, fax: +20 452960450, e-mail: m.abumandour@yahoo.com; R.M. Kandyel, Lecture in Department of Zoology, Faculty of Science, Tanta University, Egypt, e-mail: r_kandyel@science.tanta.edu.eg

This article is available in open access under Creative Common Attribution-Non-Commercial-No Derivatives 4.0 International (CC BY-NC-ND 4.0) license, allowing to download articles and share them with others as long as they credit the authors and the publisher, but without permission to change them in any way or use them commercially. 


\section{INTRODUCTION}

The bats were classified as the second-largest mammalian order (after rodent), and organized into two suborders: mega-chiropters and micro-chiropters [52]. The bats are arboreal animals [6] and the only mammalian-species naturally capable of flight [60]. Egyptian fruit bat belongs to Chiroptera order, Mega-chiroptera suborder, Pteropodidae family, Rousettus genus Rousettus aegyptiacus species $[1,6]$. The Rousettus aegyptiacus species had six subspecies, the only subspecies that live in Egypt is Rousettus aegyptiacus aegyptiacus. The feeding habit of the Pteropodidae family depends on fruit, flowers, nectar, and pollen, so these animals are classified as frugivorous species.

There are some studies on the effect of the feeding system on increasing the viability and corresponding adaptations of the structure of organs in vertebrates $[4,28]$. Generally, there are different feeding styles reported in different bat species: the blood suckling bats, insectivorous bats, and frugivorous bats [25]. Physiologically, to know the preservation tools of any vertebrate species, you must know its lingual structure $[4,14]$. The tongue is the most important structure that was modified with the distinctive nutritional ability, behaviour, and different types of available food particles [15]. Moreover, the lingual structure is modified to have different functions $[4,51]$. Furthermore, the lingual papillae are the most structures on the tongue that are most adaptable to the feeding mechanism [2].

The current investigation was prepared to give a complete morphological description of the lingual papillary system of the Egyptian fruit bat (Rousettus aegyptiacus) grossly and by the aid of the stereo, light, and scanning electron microscope (SEM). Then, the results were compared with the previous reports in other bat-species.

\section{MATERIALS AND METHODS}

\section{Collection of bat samples}

The present investigation was carried out on 12 tongues from adult Egyptian fruit bats (Rousettus aegyptiacus). The Egyptian fruit bats (Rousettus aegyptiacus) were collected from the fruit farms in the Siwa Oasis, Egypt. This study was performed in compliance with the animal care and handling rules and was approved by the Ethics Committee on Animal Experiments of the Department of Veterinary Sciences, University of Alexandria. The animals were euthanized by deep halothane inhalation, and the tongues were quickly transferred for stereo and electron microscope lab. The anatomical terms followed the Nomina Anatomica Veterinaria [47].

\section{Gross and stereomicroscopic morphological examination}

Four tongues from adult Egyptian fruit bats (Rousettus aegyptiacus) were used to describe the lingual papillary system. After euthanasia, tongues were dissected, separated, examined, and photographed using a camera (Canon IXY 325, Japan) grossly, and under a stereoscopic Zeiss Stemi 2000-C microscope (Carl Zeiss, Jena, Germany).

\section{Scanning electron microscopic examination}

Four tongues from adult Egyptian fruit bats (Rousettus aegyptiacus) were fixed in ( $2 \%$ formaldehyde, $1.25 \%$ glutaraldehyde in $0.1 \mathrm{M}$ sodium cacodylate buffer, $\mathrm{pH} \sim 7.2$ ) at $4^{\circ} \mathrm{C}$. After fixation, samples were washed in $0.1 \mathrm{M}$ sodium cacodylate containing $5 \%$ sucrose, processed through tannic acid, and finally dehydrated in ascending grades of ethanol [4]. The samples were then critical point dried in Polaron apparatus (E3000 CPD), attached to stubs with colloidal carbon, and coated with gold-palladium in a sputtering device (Pelco model 3 sputter coater 91000). Specimens were examined and photographed using a JEOL SEM (JSM-6510LV, Japan) operating at $15 \mathrm{kV}$, at the Faculty of Science, Alexandria University.

\section{Histological and histochemical investigations}

Four specimens of the Egyptian fruit bat (Rousettus aegyptiacus) tongue were dissected out and fixed in $10 \%$ formaldehyde for 48 hours at (pH 7.4), dehydrated in graded series of ethanol, cleared with xylene, and immersed in melted paraffin wax. Five- $\mu \mathrm{m}$ cutting sections were prepared. Then, samples were sectioned in 5 microns using Leica rotatory microtome (RM 20352035; Leica Microsystems, Wetzlar, Germany) and stained by haematoxylin and eosin according to Suvarna et al. [58] to demonstrate the general histological structure. Extra sections were stained by Masson's trichrome $[21,39]$ to visualise collagen and muscle fibres.

For histochemical studies, some sections were taken and stained by Alcian Blue (AB) [57] for acidic mucin; periodic acid-Schiff (PAS) [27] for neutral mucin, and double stain of $A B(\mathrm{pH}=2.5)$, and PAS (AB-PAS) technique for acidic and neutral mucin [45]. 


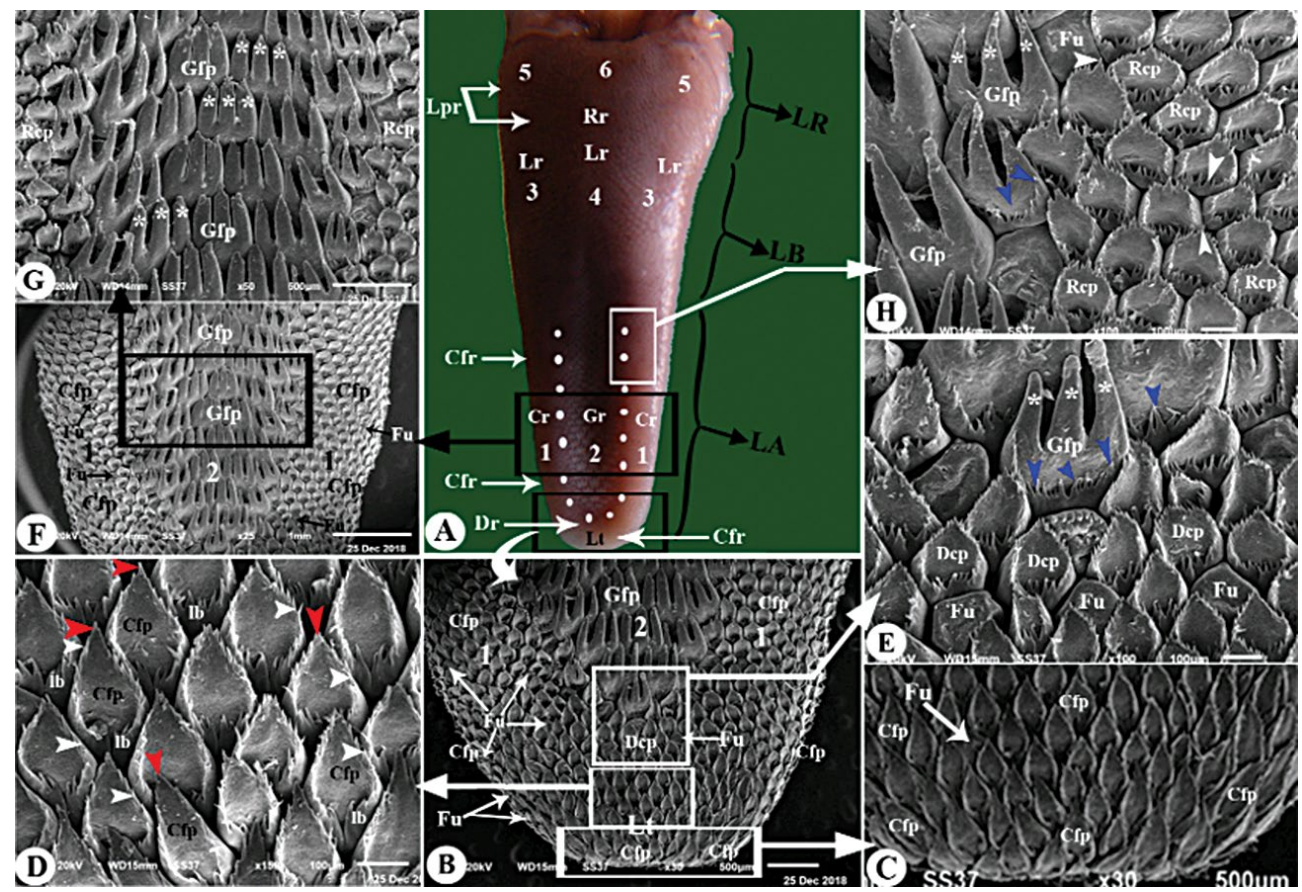

Figure 1. Gross morphological image of the tongue (A) and scanning electron microscope images (B-H) of the lingual apex of the Egyptian fruit bat. Panel A shows the lingual regions: lingual apex (LA) with its lingual tip (Lt), two lateral (1) and median parts (2) and lingual body (LB) with its two lateral (3) and median parts (4); lingual root (Lr) with its two lateral (5) and median parts (6). The seven regions of the filiform papillae: region of cornflower filiform papillae (CFr); region of diamond filiform papillae (Dr); region of giant filiform papillae (Gr); region of round and rectangular filiform papillae ( $\mathrm{Cr}$ ); region of leaf-like filiform papillae ( $\mathrm{Lr}$ ); region of rosette-like filiform papillae ( $\mathrm{Rr}$ ) and region of long pointed filiform papillae (Lpr). Panels B-H show the cornflower filiform papillae (Cfp) with the posterior pointed process (red arrowheads) and numerous processes (white arrowheads) on two elevated lateral borders that bent on the base (lb); diamond filiform papillae (Dcp); giant filiform papillae (Gfp); round and rectangular filiform papillae (Rcf), leaf-like filiform papillae (Lfp) fungiform papillae (Fu).

These sections were examined and photographed under a bright field light microscope (Olympus BX 50 compound microscope).

\section{RESULTS}

Grossly, the short tongue from the adult Egyptian fruit bat (Rousettus aegyptiacus) was divided into three parts; lingual apex (anterior free part), lingual body (middle part), and lingual root (posterior part). The dorsal lingual surface had three lingual papillary types; one mechanical that was described as filiform, and two gustatory that were described as a fungiform and circumvallate papillae. By SEM perceptions, the shape, size, number, dispersion, direction and, terminology of lingual papillae was species-specific. Their position, shape, size, number, and direction of the papillae and their very own functions were locale explicit as per the feeding propensities, mechanism of mastication, and sorts of sustenance particles. There were three main directions of all lingual papillae: posterior, posterior-median or median. The ventral lingual surface was connected to the sublingual floor by the lingual frenulum leaving a long free end of the tongue to encourage the opportunity for lingual movement. The dorsal surface of the lingual root was characterised by the presence of three circumvallate papillae.

Generally, the lingual papillae were located on the lateral region taken the posteriorly or medioposteriorly or medially directions, while that located on the median region and the lingual tip were took the posterior orientation toward the pharynx and the lingual root. The papillae on the lateral region took the different orientations to help in the collected food particles in the median region of the tongue.

\section{Gross anatomical observations}

Macroscopically, the protrusible prolonged tongue of the Egyptian fruit bats (Rousettus aegyptiacus) was ended with a round lingual apex and had two round lateral borders (Figs. 1A, 2A, 3A). In addition, every region of the tongue (apex, body, and root) was subdivided into a median and two lateral parts (Figs. 1A, 2A, 3A). 


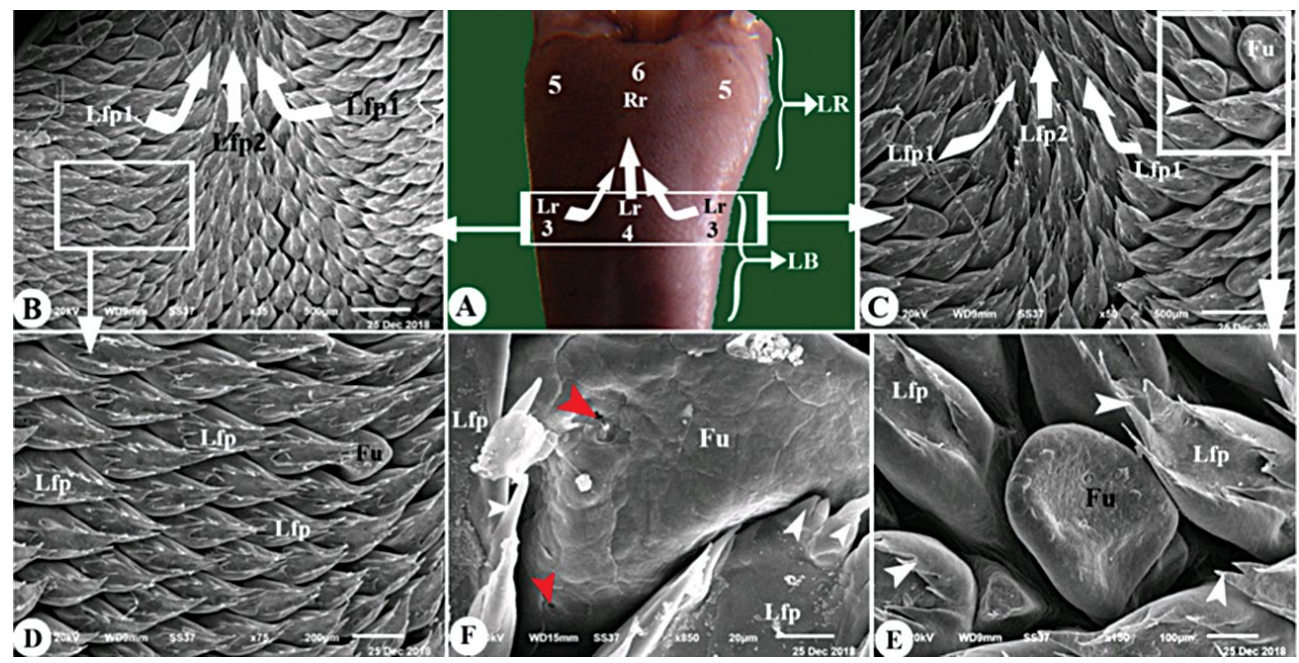

Figure 2. Gross morphological image of the lingual body and root (A) scanning electron microscope images (B-F) of the posterior part of the lingual body of the Egyptian fruit bat; Panel A shows lingual body (LB) and its two lateral (3) and median parts (4) with the region of leaf-like filiform papillae (Lr). Lingual root (LR) and its two lateral (5) and median parts (6) with region of rosette-like filiform papillae (Rr). Panels B-F show the region of leaf-like filiform papillae (Lfp1) of medioposteriorly direction on the lateral region of lingual body; region of leaf-like filiform papillae (Lfp2) of posterior direction on the median region of the lingual body. Leaf-like filiform papillae (Lpf): the processes on the margin of leaf-like filiform papillae (white arrowheads) and taste pores (red arrowheads) on the fungiform papillae (Fu).

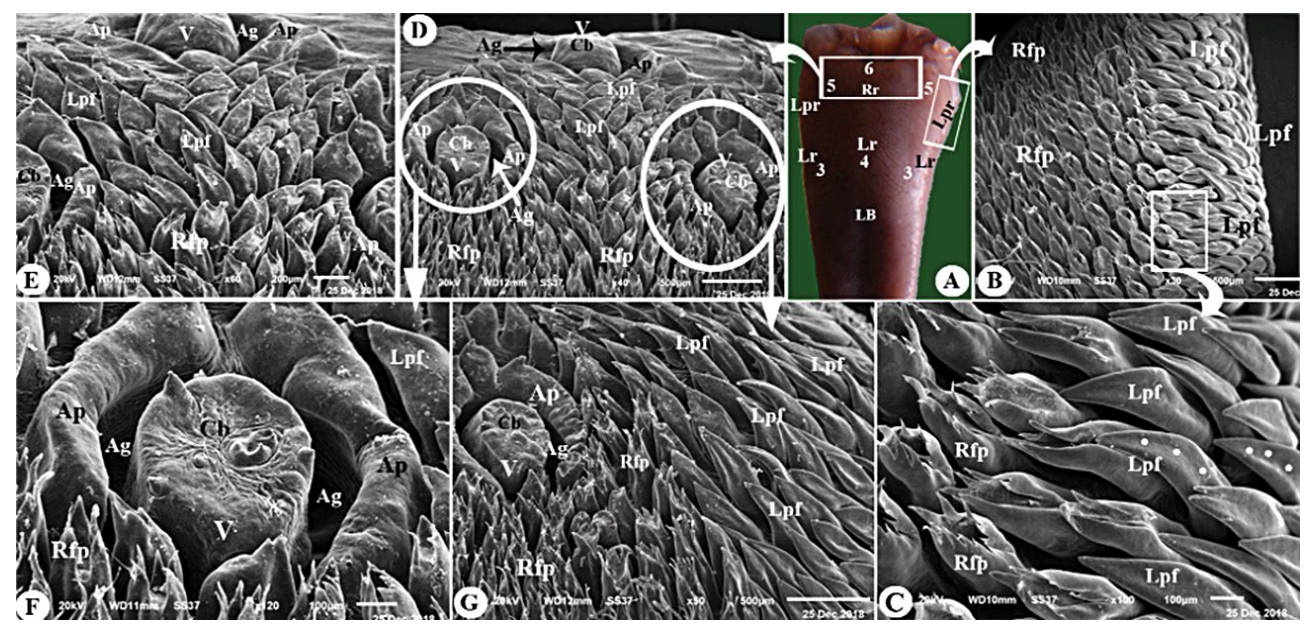

Figure 3. Gross morphological image of the lingual body and root $(\mathbf{A})$ and scanning electron microscope images (B-G) of the lingual root of the Egyptian fruit bat; Panel A shows lingual body (LB) and its two lateral (3) and median parts (4) with the region of leaf-like filiform papillae (Lr). Lingual root (LR) and its two lateral (5) and median parts (6) with the region of rosette-like filiform papillae (Rr) and region of long pointed filiform papillae (Lpr). Panels B-G show the long pointed filiform papillae (Lpf) with the groove on its dorsal surface (white dotted line); circumvallate papillae $(\mathrm{V})$ with central bulb $(\mathrm{cb})$ and surrounded by a continuous deep groove $(\mathrm{Ag})$ that is surrounded by one layer of two segmented circular annular pad (Ap).

The tongue was narrow at the anterior rostral tip, while it was broad at the lingual root. The tongue length was $1.1 \pm 0.2 \mathrm{~cm}$ yet reach $0.44 \pm 0.2 \mathrm{~cm}$ wide at its centre part. There were seven subtypes of papillae that were disseminated on seven papillary regions (Figs. 1A, 2A, 3A; Cfr, Dr, Gr, Cr, Lr, Rr, LPr).

\section{Scanning electron microscopy}

The anterior lingual region was subdivided into four U-shaped regions: lingual tip, two lateral regions, and median region (Fig. 1A, B and F; 1, 2, 3 and Lt). There were two types of lingual papillae: mechanical and gustatory papillae. 


\section{Mechanical filiform lingual papillae}

There were seven subtypes of filiform papillae that were recognised on the tongue of Egyptian fruit bats and described as follows:

Cornflower-like filiform papillae (Fig. 1B-D; (fp). Filiform papillae of this type took a posterior direction and were located on the dorsal surface of the rostral part of the lingual tip and the rostral and two lateral borders of the tongue. These papillae had apex caudally with an elongated, posteriorly directed process, and wide base rostrally and elongated body with two elevated lateral borders that bent on the base. In addition there were 8-12 posteriorly directed small, pointed processes on each lateral border (Fig. 1D; white and red arrowheads).

\section{Diamond-shaped conical filiform papillae}

(Fig. 1B, E; Dcp). These diamond-shaped conical filiform papillae were posteriorly directed and located on the dorsal surface of the median part of the lingual apex (just rostral to the region of trifid filiform papillae). These papillae had elongated apex caudally with an elongated posterior process, wide base rostrally and diamond-shaped body with non-elevated serrated borders that were curved rostrally on the base. In addition, non-elevated serrated borders had 30-32 posteriorly directed small, pointed processes.

Trifid (Giant) filiform papillae (Fig. 1B, E-H; Gfp). The trifid filiform papillae were located on the dorsal surface of the median region of the lingual apex and the anterior part of the lingual body. The organization of papillae was observed as they overlapped on each other and each papilla had a wide rectangular smooth body carrying 18-22 small pointed posteriorly directed anterior processes (Fig. 1E, 1H; blue arrowheads). While the papillar body was ended posteriorly by three posteriorly directed, large finger-like posterior processes (Fig. 1E, G, H; white*).

Round or rectangular conical filiform papillae (Fig. 1G, H; Rcp). These papillae were located on the dorsal surface of two lateral regions of the lingual apex (the area around the region of the trifid papillae) and the anterior part of the lingual body. Each papilla carried 26-28 posteriorly directed processes that arose from all borders of the papillae (Fig. $1 \mathrm{H}$; white arrowheads).

Leaf-like filiform papillae (Fig. 2; Lfp). These papillae had a different orientation; the laterally situated papillae took the median direction, while that located near the median region took the posteromedian direction, but the median situated papillae took the posterior direction (Fig. 2B, 2C; Lfp1, Lfp2). These leaf-like filiform papillae were located on all dorsal surface of the posterior part of the lingual body; each papilla had an ovoid-shaped body that carried 14-16 posteriorly directed processes that originated from all borders (Fig. 2C-F; white arrowheads).

Rosette-like filiform papillae (Fig. 3; Rfp). These papillae were located on the dorsal surface of the median part and the areas of the two lateral parts near the median part of the lingual root till the beginning of the triangular region of the circumvallate papillae. Each papilla had a round base and body with an apex that terminated by posteriorly directed numerous small processes forming a basket-like shape (Fig. 3C; Rfp).

Long pointed filiform papillae (Fig. 3; Lpf). These papillae were located on the lateral border (Fig. 3B, C; Lpf), in addition to the triangular area of circumvallate papillae (Fig. 3D, E; Lpf) and the small area posterior to the triangular area (Fig. 3F, G; Lpf). The papillae that were situated on the lateral border took the median direction while that on the lateral region took the posteromedian direction, but those located on the triangular area of the circumvallate papillae took the posterior direction. Each papilla overlapped the other in the form of the long pointed tongue-shaped papilla without any secondary processes, with a central groove (Fig. 3C; dotted line).

\section{Gustatory lingual papillae}

The gustatory papillae were recorded with characteristic position, dispersion, and number all through the entire tongue length. These papillae were the fungiform and circumvallate papillae, and described as follows.

Fungiform papillae. There were scanty numbers of the fungiform papillae randomly distributed among the filiform papillae on the lingual tip (Fig. 1B, C, E; $\mathrm{Fu}$ ) and the two lateral parts of the lingual apex and body (Fig. 1F; Fu). while the fungiform papillae were completely absent in the median lingual part (region of trifid filiform papillae and leaf-like filiform papillae and the median region of the lingual root). There was one shape of the fungiform papillae, they had quadrilateral appearance. The dorsal surface of the fungiform papillae had micro-ridges and micro-scales in addition to the one or two small depressions for taste pores (Fig. 2F; red arrowheads).

Circumvallate papillae (Fig. 3D-G; V). There were three rounded circumvallate papillae distributed on 
the posterior part of the lingual root that took the triangular arrangement; its base was directed rostrally with two laterally located papillae while its apex was directed posteriorly with one median located papilla. Each papilla consisted of a round central bulb surrounded by a continuous deep papillary groove (Fig. 3D-G; cb, Ag). The central round bulb was surrounded by one layer of two segmented circular annular pad laterally, but from the rostral and posterior side it was not surrounded by this circular pad (Fig. 3D-G; Ap). The dorsal surface of the central bulb had an irregular surface with microtubercles, microfolds, microgrooves, and numerous taste buds (Fig. 3F).

\section{Light microscopic examination}

Histological observation of the tongue of the Egyptian fruit bat (Rousettus aegyptiacus) cleared three types of lingual papillae (filiform, circumvallate, and fungiform papillae) with different subtypes and densities that distributed over the whole dorsal lingual surface of the tongue. Each papilla was covered by a keratinised multilayered stratified squamous epithelium and supported by connective tissue core, and underneath the lamina propria and muscle fibre layers. The lingual apex showed numerous filiform papillae that were widely dispersed over the dorsal surface, their tips were pointed posteriorly (Fig. 4A, B). Dense connective tissue rich with collagen fibres and blood vessels penetrated deeply into the core of the papillae and continued with the underneath connective tissue layer (Fig. 4C).

At the lingual body, the dorsal epithelium showed numerous fungiform papillae with a quadrilateral appearance. Their epithelium was covered by a thin detached keratin layer and containing few taste buds (Fig. 4D-F). The three triangularly arranged circumvallate papillae covered the dorsal surface of the lingual root. The papillae were covered with a keratinised mucosal surface (Fig. 5A, B). They were also supported by collagen connective tissue fibres and skeletal muscle bundles. Collagen fibres, lymphoid cells, and blood vessels occupied the connective tissue layer and were supported by an underlying layer of muscle fibres arranged in many directions. Abundant fatty cells were seen between the bundles of muscle fibres (Fig. 5C).

Histochemical results revealed that the lingual glands displayed a stronger $A B$-positive reaction and gave dark blue colour (Fig. 6A, B), while the reaction for the PAS-stain was negative (Fig. 6C, D). In addition,

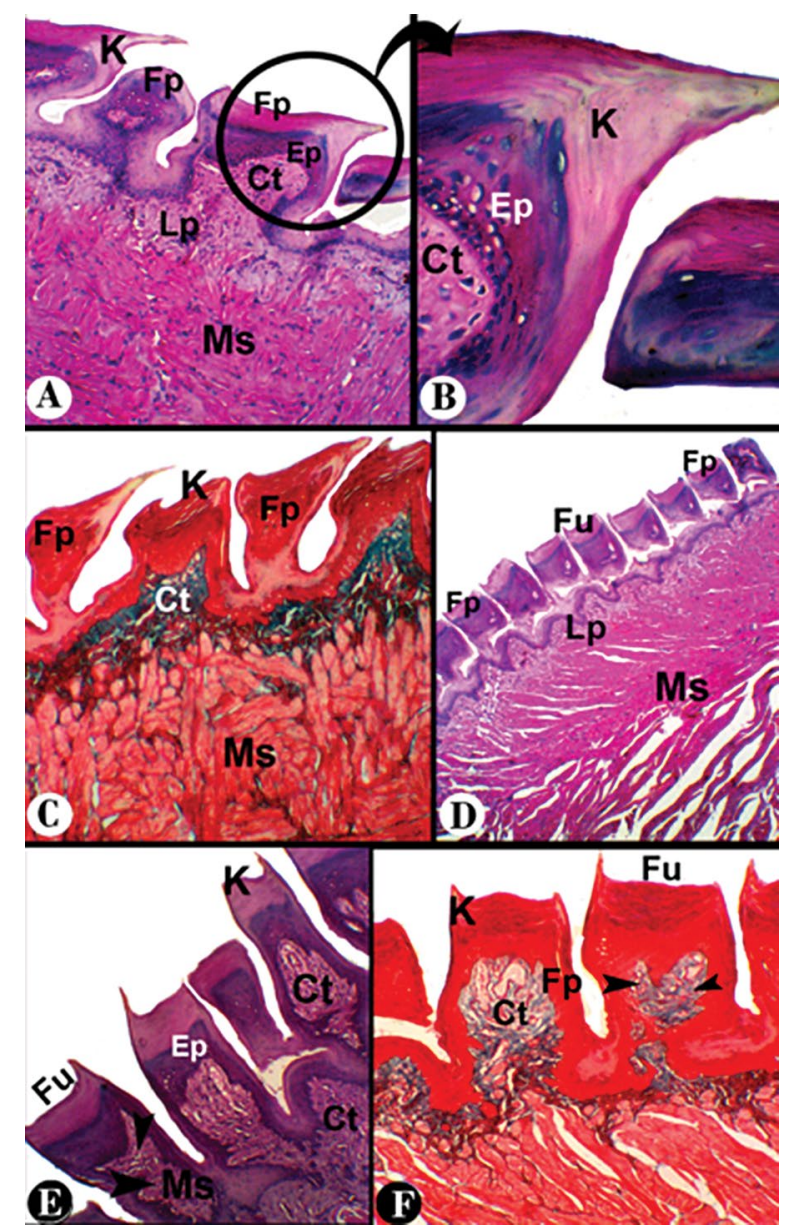

Figure 4. Histological image of the lingual apex (A-C) and body (D-F) of the Egyptian fruit bat; Panel A represent the dorsal view of the lingual apex of the Egyptian fruit bat (Rousettus aegyptiacus), panel $B$ represents the higher magnification of the filiform papillae (Fp); haematoxylin and eosin. Panel C represents the Masson's trichrome stain of the lingual apex to clear the collagen connective tissue $(\mathrm{Ct})$. Panel $\mathrm{D}$ represents the dorsal view of the lingual body of the Egyptian fruit bat (Rousettus aegyptiacus), and panel E represents the higher magnification of the dorsal view of the lingual body of the Egyptian fruit bat (Rousettus aegyptiacus); haematoxylin and eosin. Panel F represents the Masson's trichrome stain of the lingual body of the Egyptian fruit bat (Rousettus aegyptiacus). Filiform papillae $(\mathrm{Fp})$ with a thick keratinised layer $(\mathrm{K})$, the dorsal epithelium (Ep), lamina propria (Lp), connective tissue core (Ct), muscles (Ms), fungiform papillae (Fu), and the black arrowheads refer to the taste buds in the fungiform papillae.

the glands exhibited a blue colour as an indication of positive $A B$ reactivity with combined $A B$-PAS staining (Fig. 6E, F).

\section{DISCUSSION}

The variations of the feeding mechanism with the different available feeding particles were reflected on the position, structure, number, shape, nomination and, orientation of the lingual papillae $[2,4,14,19,26]$. 


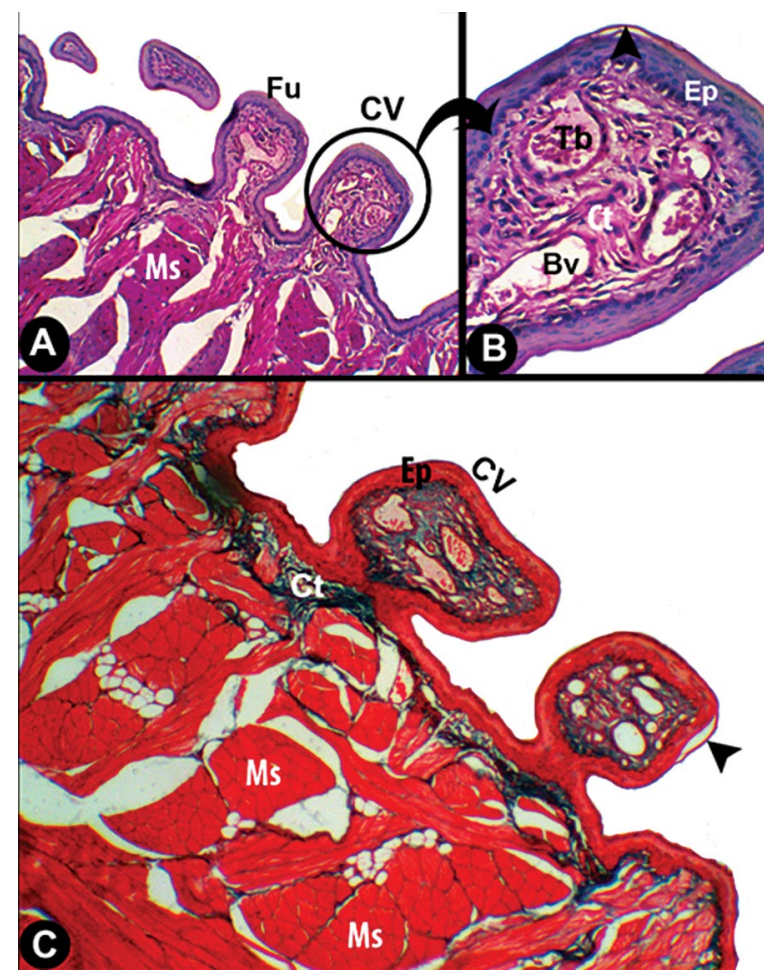

Figure 5. Histological image of the lingual root (A-C) of the Egyptian fruit bat; Panel A represents the dorsal view of the lingual root of the Egyptian fruit bat (Rousettus aegyptiacus), panel B represents the higher magnification of the circumvallate papillae (CV); haematoxylin and eosin stain. Panel C represent the Masson's trichrome (Alcian Blue) stain of the lingual root to clear the collagen connective tissue (Ct). The dorsal epithelium (Ep), connective tissue core (Ct), lingual muscles (Ms), circumvallate papillae (CV) with a keratinised layer (black arrowhead), taste bud (Tb), and blood vessel (Bv).

The common example for the adaptation of the different bat-species to the different feeding mechanism with the feeding on different food particles during the flying lead to the species-variations in the morphological appearance of the lingual papillae, as appeared in the previously published data $[4,7,15$, $44,51,55]$ and confirmed by the current study on the two bat-species of the different feeding mechanism. The mammalian tongue exhibited numerous morphological adaptations to perform numerous functions including the food particles collection, manipulation, and direction of the food particles towards the oesophagus $[4,28]$.

The tongue of the Egyptian fruit bat (Rousettus aegyptiacus) was described as subdivided into three regions, lingual apex, body, and root, similar to those reported in all vertebrate species $[4,7,14,23,28]$. Moreover, in the Egyptian fruit bat, there was a sub-

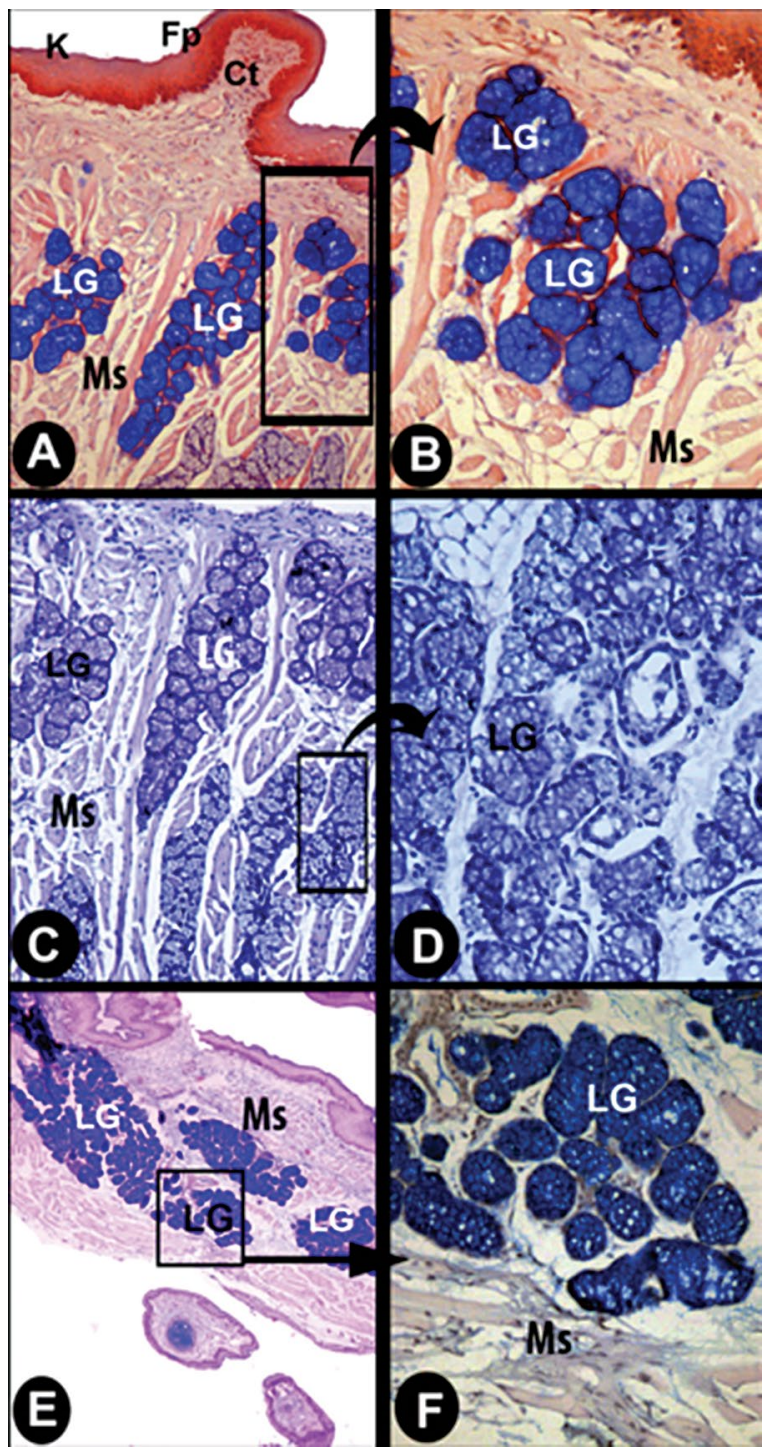

Figure 6. Transverse histological image of the lingual root (A-F) of the Egyptian fruit bat; Panels $A$ and $B$ represent the transverse sections of the tongue of the Egyptian fruit bat (Rousettus aegyptiacus) showing a positive acidic mucin reaction of the lingual glands (LG); Alcian Blue (AB) stain. Panels $C$ and $D$ represent the transverse sections of the tongue of the Egyptian fruit bat (Rousettus aegyptiacus) showing a negative neutral mucin reaction of the lingual glands (LG); periodic acid-Schiff (PAS) stain. Panels $E$ and $F$ represent the transverse sections of the tongue of the Egyptian fruit bat (Rousettus aegyptiacus) showing a positive $A B$ reaction and a negative PAS reaction of the lingual glands (LG); AB-PAS stain. Circumvallate papillae (CV), keratinised layer (K), and connective tissue core $(\mathrm{Ct})$, lingual gland $(\mathrm{LG})$, and lingual muscles $(\mathrm{Ms})$.

division of these three regions into two lateral and single median parts. In addition, the anterior lingual region was subdivided into four U-shaped regions: lingual tip, two lateral regions and median region. Also, these subdivision parts were carrying lingual papillae of different 
shape, orientation, nomination, and function, similar to that observed by Abumandour et al. [4], El-Mansi et al. [15] and Massoud and Abumandour [41].

Morphologically, most researchers focused on the description of the lingual papillae due to their direct relationship with the feeding style of each species and available food particles [28]. Functionally, the papillary system was adapted and this appears in the structure, number, appearance, orientation, and dispersion of the lingual papillae [4]. The present description confirmed that the lingual papillae can be classified functionally into mechanical and gustatory papillae according to their specific function $[4,7,15$, $19,34]$. Moreover, these papillae were described as three types in Egyptian fruit bat (Rousettus aegyptiacus): one mechanical papilla that was described as filiform and two gustatory papillae that were described as fungiform and circumvallate. These findings were similar to that reported in some bats species $[19,43$, $49,51]$. On the other hand, Abumandour et al. [4] and El-Mansi et al. [15] vobserved the presence of four types of lingual papillae: two mechanical and two gustatory in Egyptian fruit bat (Rousettus aegyptiacus). However Masuko et al. [43] observed the presence of two types of lingual papillae; filiform and fungiform in hematophagous bats.

The lingual filiform papillae had species-specific and region-specific characterisation and were described as the lingual papillae structure adapted to the feeding mechanism and the available food particles. For that reason, the filiform papillae had a characteristic appearance and functional adaptation and this appears in their characteristic shape, subdivision, number, directions, and positions [2]. Functionally, the subdivision of the filiform papillary system is the most important classification of due to their important role in food particles intake and transportation $[2,4,15]$. The anatomical subdivision of the lingual filiform was reported previously in the published articles especially in bat [2]. The filiform papillary system was subdivided into seven subtypes as reported in the current work in the Egyptian fruit bat (Rousettus aegyptiacus), similar to that findings of Park and Hall [48] in bat; however, some authors observed six subtypes in Egyptian fruit bat (Rousettus aegyptiacus) [4] and Japanese long-fingered bats [37]. Five subtypes were noted in lesser dog-faced fruit and nectarivorous bats $[19,43]$, and four subtypes were reported in frugivorous bats $[43,46]$ and Egyptian fruit bat (Rousettus aegyptiacus) [15]. Three subtypes were observed by Pastor et al. [51], Jackowiak et al. [34], and Park and Lee [49].

Another factor affecting the anatomical subdivision of the filiform papillae is the geographical distribution of the bats. This adaptation appears in some cases. The first case is the little red flying-fox bat that feeds on nectar, so its filiform papillary system adapted by the presence of numerous long giant pointed filiform papillae on the lingual apex $[8,12]$, while when subjected to the migration to research on food particles other than nectar-feeding, the filiform papillary system modified to depend on the feeding on fruit instead of nectar-feeding [13]. The second case is the Egyptian fruit bat caught from the fruit farms in the Nile Delta of Egypt, which had the filiform papillary system divided into six subtypes $[2,4]$, whereas that caught from the fruit farms in the Siwa Oasis of Egypt in the current study carried seven subtypes. Moreover the bat caught from Japan had five subtypes, the bat caught from Saudi Arabia carried four subtypes only [15], and that caught from Poland had only three subtypes [34]. The third case was observed in the filiform papillary system on the lingual tip; the current study reported that the Egyptian fruit bat carried cornflower filiform papillae, while in the Egyptian fruit bat caught from Poland, the lingual tip had numerous small filiform papillae [34], and in that caught from Japan, the lingual tip had numerous scales-like filiform papillae [20]. The current findings agree with previously published data $[2,15,62]$ that the anatomical shape, distribution, and nomination of the lingual papillae had characteristic features that reflected on the evolutionary taxonomic status of the bat species $[15,63]$.

The gustatory fungiform papillae were subjected to three main classifications. The first classification is according to their function and had three types of the gustatory papillae, as in that shown in the current work in Egyptian fruit bat (Rousettus aegyptiacus). The same results were described by Abumandour and El-Bakary [4], El-Mansi et al. [15], Massoud and Abumandour [41] and Abumandour and El-Bakary [3]. The second one is named the mechanical papilla and does not have any taste buds; this type has not been recorded in any bat species, but was noted in other species, such as donkey [40]. The third one is the mixed type in which some papillae had taste buds and other do not have any in the same animal, as was shown in Australian Megachiroptera [7]. The second classification is according to the distribution of these papillae, as described by Chung and Kwun [9]. 
The first one described that these papillae were found on the entire lingual length [49] in bats, but the second one described that these papillae were found on the lingual boundaries [50] in S. species; however, the third one described that these papillae were found on the lingual tip and side edge areas, as observed in fruit bat [4, 19] and flying squirrel [17], while the fourth one noted the presence of these papillae at the lingual centre and tip as reported in bank vole and Japanese grass vole $[24,31]$. Moreover, the present study described that the scanty numbers of these papillae were found on the lingual tip and the two lateral parts of the lingual apex and body, while these papillae were completely absent in the median lingual part, similar to that described by Abumandour and El-Bakary [4]. The third classification is according to the shape of these papillae. From the previously published data, all species had only one shape that differs from species to species. The present study observed the quadrilateral shape, similar to that described by El-Mansi et al. [15] in Egyptian fruit bat captured from Saudi Arabia, while that captured from Egypt had the dome-shaped fungiform papillae, as reported by Massound and Abumandour [41]; the round fungiform papillae were recorded by El-Bakary and Abumandour [14] in the Egyptian Water Buffalo (Bubalus bubalis), the elliptical shape [49], the domeshaped fungiform papillae [17] in the flying squirrel, the mushroom shape [38], the discoid fungiform observed by El-Mansi et al. [15] in Egyptian tomb bat, and the fungus shape fungiform observed by Dinc et al. [11] in the rat. While in Egyptian fruit bat observed the presence of two shapes of the fungiform papillae: rectangular and round [4].

According to the previously published articles, there are species variations in the number, shape, distribution, position, and shape of its lingual dorsal surface with taste buds. The most characteristic point is the number of the circumvallate papillae that differ from the completely absent to more than 20 papillae. The circumvallate papillae are completely absent in the blood-drinking Desmodus rotundus and haematophagous bats $[25,43]$, but the presence of only one circumvallate papilla has been observed in some mammalian species [16, 42]. Moreover, the most common number is the presence of two papillae as reported in common European bat [51], Korean greater horseshoe bat [56], lesser dog-faced fruit and flying fox $[18,19]$, free-tailed bat [26], and Korean long-fingered bats [50]. However, we found the presence of three circumval- late papillae in the present study in Egyptian fruit bat (Rousettus aegyptiacus), similar to that described by Abumandour et al. [4], El-Mansi et al. [15], Jackowiak et al. [34], and Massoud et al. [41] in Egyptian fruit bat [18, 19], in frugivorous bats [7], in S. australis and Pteropus [46], in E. wahlbergi, and the long-eared hedgehog $(H$. auritus) [42]. Moreover, four circumvallate papillae were described by Masuko et al. [43] in long-nosed bat and frugivorous and nectarivorous bats [7] as well as in Australian Megachiroptera (N. Robinsoni). However, there were some mammalian species that carried several circumvallate lingual papillae, such as deer [64] and buffalo [14].

The circumvallate papillae had a round central bulb encircled by a continuous deep groove in Egyptian fruit bat (Rousettus aegyptiacus), similar to that described by Abumandour et al. [4], Ciuccio et al. [10] and El-Mansi et al. [15]. Moreover, the present investigation described that the central round bulb was encircled only by one layer of two segmented circular annular pad laterally but, from the rostral and posterior side, not surrounded by this circular pad. There was some variation in the number of pad layers surrounding the circumvallate papillae; the presence of only one layer of the annular pad was observed in mouse, rat and other rodents [29,30], and primates [36], while the two layers of the pad were observed in some bat species $[4,50]$.

The dorsal surface of the circumvallate papillae had an irregular surface by the SEM observations. The same findings were described by Aboelnour et al. [4] and El-Mansi et al. [15] in Egyptian fruit bat and in the rabbit [3]. However, the smooth papillary surface was recorded in fox [32].

The triangular arrangement of the circumvallate papillae was a characteristic appearance that appeared in some mammalian species. The present examination on the two bat species of various feeding habits had this triangular arrangement of the circumvallate papillae, like that revealed in fruit bat $[4,15$, 18, 34, 41, 46], Egyptian long-eared hedgehog [42], and the Persian squirrel [53].

The obtained histological findings showed that the dorsal surface of the tongue was covered with a thick keratinised multilayered stratified squamous epithelial layer that covered all the dorsal surface with its papillae, similar results were recorded by Abumandour and El-Bakary [4], El-Mansi [15] and Massoud and Abumandour [41] in the Egyptian fruit bat (Rousettus aegyptiacus). 
The obtained histological findings showed that there were numerous taste buds in both fungiform and circumvallate papillae in the Egyptian fruit bat (Rousettus aegyptiacus) tongue. The taste buds were also recorded in most bat species: in the Egyptian tomb bat (Taphozous perforatus) [16] and in the Egyptian fruit bat (Rousettus aegyptiacus) [15, 41].

The present results corresponding with that reported by Goździewska-Harłajczuk et al. [23], Jackowiak et al. [34], and Iwasaki et al. [30] that the presence of the taste buds was related to the process of chemoreception of the gland secretion of the tongue. Furthermore, the description of the lingual glands in the current work matched with the obtained results of Akbari et al. [5], Goździewska-Harłajczuk [22], Jarrar et al. [35], and Tandler et al. [59].

In vertebrate animals, the lingual gland secretions act as a lubricant that assists in moistening the food particles, then facilitates food movements, transport, and swallowing [33, 54, 61]. The current histochemical results revealed that the lingual glands showed a stronger $A B$-positive reaction and gave dark blue colour, while the reaction for the PAS-stain was negative. This negative reaction with PAS-stain was similar to that noted by Massoud and Abumandour [41]. The current study reported that the glands give a blue colour as an indication of positive $A B$ reactivity with combined AB-PAS staining, while Massoud and Abumandour [41] reported the $A B$ positive granules with blue colour stain of the acidic mucins.

\section{Funding}

Taif University Researchers Supporting Project number (TURSP-2020/138), Taif University, Taif, Saudi Arabia.

\section{Acknowledgements}

The authors would like to express their gratitude to the Anatomy and Embryology Department, Faculty of Veterinary Medicine, Alexandria University for providing technical and administrative support. Also, we are indebted to the Zoology Department, Faculty of Science, Tanta University. We deeply thank Taif University Researchers Supporting Project number (TURSP-2020/138), Taif University, Taif, Saudi Arabia.

\section{Conflict of interest: None declared}

\section{REFERENCES}

1. Aboelnour A, Noreldin AE, Massoud D, et al. Retinal characterization in the eyes of two bats endemic in the Egyptian fauna, the Egyptian fruit bat (Rousettus aegyp- tiacus) and insectivorous bat (Pipistrellus kuhlii), using the light microscope and transmission electron microscope. Microsc Res Tech. 2020; 83(11): 1391-1400, doi: 10.1002/ jemt.23530, indexed in Pubmed: 33405350.

2. Abumandour M. Morphological Comparison of the Filiform Papillae of New Zealand White Rabbits (Oryctolagus cuniculus) as Domestic Mammals and Egyptian Fruit Bat (Rousettus aegyptiacus) as Wild Mammals Using Scanning Electron Microscopic Specimens. Int J Morphol. 2014; 32(4): 1407-1417, doi: 10.4067/s071795022014000400045.

3. Abumandour MMA, El-Bakary RMA. Anatomic reference for morphological and scanning electron microscopic studies of the New Zealand white rabbits tongue (Orycotolagus cuniculus) and their lingual adaptation for feeding habits. J Morphol Sci. 2013; 30(4): 1-12.

4. Abumandour MMA, El-Bakary RMA. Morphological and scanning electron microscopic studies of the tongue of the Egyptian fruit bat (Rousettus aegyptiacus) and their lingual adaptation for its feeding habits. Vet Res Commun. 2013; 37(3): 229-238, doi: 10.1007/s11259-013-9567-9, indexed in Pubmed: 23709139.

5. Akbari G, Babaei M, Hassanzadeh B. Morphological study of the European hedgehog (Erinaceus europaeus) tongue by SEM and LM. Anat Sci Int. 2018; 93(2): 207-217, doi: 10.1007/s12565-017-0391-0, indexed in Pubmed: 28160234.

6. Altringham JD, McOwat T, Hammond L. Bats: biology and behaviour. Oxford University Press, Oxford 1996.

7. Birt P, Hall L, Smith G. Ecomorphology of the Tongues of Australian Megachiroptera (Chiroptera: Pteropodidae). Austr J Zool. 1997; 45(4): 369, doi: 10.1071/zo97005.

8. Boland DJ. Forest Trees of Australia. Thomas Nelson, Melbourne 1984.

9. Chung YW, Kwun HS. A morphological study on the tongues of the vertebrates. I. Comparative macroscopic and microscopic observations. J Catholic Medical College (Korean). 1977; 30: 531-555.

10. Ciuccio M, Estecondo S, Casanave EB. Scanning electron microscopy study of the dorsal surface of the tongue of dasypus hybridus (Mammalia, Xenarthra, Dasypodidae). Int J Morphol. 2010; 28(2), doi: 10.4067/s071795022010000200007.

11. Dinç G, Girgin A, Yllmaz S. Ratlarda papilla fungiformis'in prenatal ve postnatal gelişimi. FFrat Üniv SağlFk Bil Derg. 1995; 9(2): 161-163.

12. Eby P. Finger-winged night workers: managing forests to conserve the role of grey-headed flying foxes as pollinators and seed dispersers. In: Lunney D. (ed.). Conservation of Australias Forest Fauna. Royal Zoological Society of New South Wales, Mosman 1991: 91-100.

13. Eby P. The biology and management of flying foxes in New South Wales. New South Wales National Parks and Wildlife Service, Report No. 18, 1995.

14. El-Bakary NER, Abumandour MMA. Morphological studies of the tongue of the egyptian water buffalo (bubalus bubalis) and their lingual papillae adaptation for its feeding habits. Anat Histol Embryol. 2017; 46(5): 474-486, doi: 10.1111/ahe.12292, indexed in Pubmed: 28833390.

15. El-Mansi A, Al-Kahtani MA, Abumandour M. Comparative phenotypic and structural adaptations of tongue and gastrointestinal tract in two bats having different 
feeding habits captured from Saudi Arabia: Egyptian fruit bat (Rousettus aegyptiacus) and Egyptian tomb bat (Taphozous perforatus). Zoologischer Anzeiger. 2019; 281: 24-38, doi: 10.1016/j.jcz.2019.05.005.

16. El-Sharaby AA, El-Gendy SA, Alsafy MA, et al. Morphological variations of the vallate papillae in some mammalian species. Anat Sci Int. 2014; 89(3): 161-170, doi: 10.1007/ s12565-013-0215-9, indexed in Pubmed: 24242871.

17. Emura S, Tamada A, Hayakawa D, et al. SEM study on the dorsal lingual surface of the flying squirrel, Petaurista leucogenys. Ann Anat - Anatomischer Anzeiger. 1999; 181(5): 495-498, doi: 10.1016/s0940-9602(99)80033-8.

18. Emura S, Hayakawa D, Chen $\mathrm{H}$, et al. SEM study on the dorsal lingual surface of the large flying fox, Pteropus vampyrus. Okajimas Folia Anat Jpn. 2002; 79(4): 113-119, doi: 10.2535/ofaj.79.113, indexed in Pubmed: 12484446.

19. Emura S, Hayakawa D, Chen $H$, et al. SEM study on the dorsal lingual surface of the lesser dog-faced fruit bat, Cynopterus brachyotis. Okajimas Folia Anat Jpn. 2001; 78(4): 123-128, doi: 10.2535/ofaj1936.78.4_123, indexed in Pubmed: 11774747.

20. Emura S, Okumura T, Chen H. Morphology of the lingual papillae in the Egyptian rousette bat (Rousettus aegyptiacus). Okajimas Folia Anat Jpn. 2012; 89(3): 61-66, doi: 10.2535/ofaj.89.61, indexed in Pubmed: 23429050.

21. Gewily DI, Mahmoud FA, Saber SA, et al. Ultrastructural comparison between the tongue of two reptilian species endemic in Egyptian fauna; Bosc's fringe-toed lizard Acanthodactylus boskianus and Sinai fan-fingered gecko Ptyodactylus guttatus. Microsc Res Tech. 2021; 84(9): 1977-1991, doi: 10.1002/jemt.23753, indexed in Pubmed: 33720486.

22. Goździewska-Harłajczuk K, Klećkowska-Nawrot J, Nowaczyk R, et al. Biological aspect of the surface structure of the tongue in the adult red kangaroo (Macropus rufus): light and scanning electron microscopy. Biologia. 2016; 71(6): 174-178, doi: 10.1515/biolog-2016-0082.

23. Goździewska-Harłajczuk K, Klećkowska-Nawrot J, Barszcz K, et al. Biological aspects of the tongue morphology of wild-captive WWCPS rats: a histological, histochemical and ultrastructural study. Anat Sci Int. 2018; 93(4): 514-532, doi: 10.1007/s12565-018-0445-y, indexed in Pubmed: 29948977.

24. Grandi D, Arcari ML, Azalli G. Ultrastructural aspects of the lingual papillae in the gerbil (Meriones unguiculatus). Ital J Anat Embryol. 1994; 99: 201-217.

25. Greenbaum IF, Phillips CJ. Comparative anatomy and general histology of tongues of long-nosed bats (Leptonycteris sanborni and L. nivalis) with reference to infestation of oral mites. J Mammal. 1974; 55(3): 489-504, indexed in Pubmed: 4851092.

26. Gregorin R. Comparative morphology of the tongue in free-tailed bats (Chiroptera, Molossidae). Iheringia. Série Zoologia. 2003; 93(2): 213-221, doi: 10.1590/s007347212003000200014

27. Humason GL. Animal tissue techniques. Animal tissue techniques, 1962.

28. Iwasaki Si. Evolution of the structure and function of the vertebrate tongue. J Anat. 2002; 201(1): 1-13, doi: 10.1046/j.1469-7580.2002.00073.x, indexed in Pubmed: 12171472.

29. Iwasaki S, Yoshizawa H, Kawahara I. Study by scanning electron microscopy of the morphogenesis of three types of lingual papilla in the mouse. Acta Anat (Basel). 1996; 157(1): 41-52, doi: 10.1159/000147865, indexed in Pubmed: 9096741.

30. Iwasaki S, Yoshizawa H, Kawahara I. Study by scanning electron microscopy of the morphogenesis of three types of lingual papilla in the rat. Anat Rec. 1997; 247(4): 528-541, doi: 10.1002/(SICI)1097-0185(199704)247:4<528::AIDAR12>3.0.CO;2-R, indexed in Pubmed: 9096793.

31. Jackowiak $\mathrm{H}$, Godynicki S. The distribution and structure of the lingual papillae on the tongue of the bank vole Clethrinomys glareolus. Folia Morphol. 2005; 64(4): 326-333, indexed in Pubmed: 16425161.

32. Jackowiak H, Godynicki S. The scanning electron microscopic study of lingual papillae in the silver fox (Vulpes vulpes fulva, Desmarest, 1820). Ann Anat. 2004; 186(2): 179-183, doi: 10.1016/S0940-9602(04)80037-2, indexed in Pubmed: 15125050.

33. Jackowiak $\mathrm{H}$, Ludwig $M$. Light and scanning electron microscopic study of the structure of the ostrich (Strutio camelus) tongue. Zoolog Sci. 2008; 25(2): 188-194, doi: 10.2108/zsj.25.188, indexed in Pubmed: 18533750.

34. Jackowiak H, Trzcielińska-Lorych J, Godynicki S. The microstructure of lingual papillae in the Egyptian fruit bat (Rousettus aegyptiacus) as observed by light microscopy and scanning electron microscopy. Arch Histol Cytol. 2009; 72(1): 13-21, doi: 10.1679/aohc.72.13, indexed in Pubmed: 19789409.

35. Jarrar BM, Taib N. Histochemical characterization and distribution of mucosubstances and enzyme activity in the lingual salivary glands of the one-humped camel (Camelus dromedarius). Revue d'élevage et de médecine vétérinaire des pays tropicaux. 1989; 41(1): 63-71.

36. Kobayashi K, Kumakura M, Yoshimura K, et al. Comparative morphological studies on the stereo structure of the lingual papillae of selected primates using scanning electron microscopy. Ann Anat. 2004; 186(5-6): 525-530, doi: 10.1016/ S0940-9602(04)80101-8, indexed in Pubmed: 15646287.

37. Kobayashi S, Shimamura A. Comparative anatomical observations of the tongue of the Japanese long-fingered bats, Miniopterus schreibersi fuliginosus. Okajimas Folia Anat Jpn. 1982; 58(4-6): 923-932, doi: 10.2535/ ofaj1936.58.4-6_923, indexed in Pubmed: 7122024.

38. Kurtul I, Atalgın $\mathrm{SH}$. Scanning electron microscopic study on the structure of the lingual papillae of the Saanen goat. Small Ruminant Res. 2008; 80(1-3): 52-56, doi: 10.1016/j. smallrumres.2008.09.003.

39. Luna LG. Routine staining procedures. Manual of histologic staining methods of the Armed Forces Institute of Pathology. Blakiston Division, McGraw-Hill, New York 1968: 33-46.

40. Mahmoud MMAE, Ahmed EZ, Rudolf L, et al. Morphological characteristics of the tongue and its papillae in the donkey (Equus asinus): a light and scanning electron microscopical study. Ann Anat Anatomischer Anzeiger. 2002; 184(5): 473-480, doi: 10.1016/s09409602(02)80081-4.

41. Massoud D, Abumandour MMA. Anatomical features of the tongue of two chiropterans endemic in the Egyptian fauna; the Egyptian fruit bat (Rousettus aegyptiacus) and insectivorous bat (Pipistrellus kuhlii). Acta Histochem. 2020; 122(2): 151503, doi: 10.1016/j.acthis.2020.151503, indexed in Pubmed: 31955907. 
42. Massoud D, Abumandour MMA. Descriptive studies on the tongue of two micro-mammals inhabiting the Egyptian fauna; the Nile grass rat (Arvicanthis niloticus) and the Egyptian long-eared hedgehog (Hemiechinus auritus). Microsc Res Tech. 2019; 82(9): 1584-1592, doi: 10.1002/ jemt.23324, indexed in Pubmed: 31225934.

43. Masuko TS, et al. Comparative Scanning Electron Microscopic Study of the Lingual Papillae in Three Species of Bats (Carollia perspicillata, Glossophaga soricina and Desmodus rotundus). Microsc Microanal. 2007; 13(Suppl 2): 280-281.

44. Morrison DW. Efficiency of food utilization by fruit bats. Oecologia. 1980; 45(2): 270-273, doi: 10.1007/ BF00346469, indexed in Pubmed: 28309539.

45. Mowry RW. Alcian blue technics for the histochemical study of Alcian carbohydrates. J Histochem Cytochem. 1956; 4: 407-411.

46. Mqokeli BR, Downs CT. Palatal and lingual adaptations for frugivory and nectarivory in the Wahlberg's epauletted fruit bat (Epomophorus wahlbergi). Zoomorphology. 2012; 132(1): 111-119, doi: 10.1007/s00435-012-0170-3.

47. Nomina Anatomica Veterinaria N. International Committee on Veterinary Gross Anatomical Nomenclature and authorized by the general assembly of the world Association of veterinary Anatomist. Knoxville, 3rd Ed. Ghent. Published by the Editorial Committee Hanover (Germany), Ghent (Belgium), Columbia, MO (USA), Rio de Janeiro (Brazil). 2017.

48. Park H, Hall E. The gross anatomy of the tongues and stomachs of eight new world bats. Trans Kans Acad Sci (1903-). 1951; 54(1): 64-72, doi: 10.2307/3626255.

49. Park J, Lee JH. Comparative Morphology of the Tongue of Miniopterus schreibersi fuliginosus and Pipistrellus savii. Applied Microscopy. 2009; 39(3): 267-276.

50. Park J, Lee JH. Morphological Study on the Dorsal Lingual Papillae of Sorex caecutiens Laxmann. Korean J Microscopy. 2009; 39(2): 106-106.

51. Pastor JF, Moro JA, Verona JA, et al. Morphological study by scanning electron microscopy of the lingual papillae in the common European bat (Pipistrellus pipistrellus). Arch Oral Biol. 1993; 38(7): 597-599, doi: 10.1016/00039969(93)90125-6, indexed in Pubmed: 7690226.

52. Prothero DR. The Princeton field guide to prehistoric mammals. Vol. 112. Princeton University Press 2016.

53. Sadeghinezhad J, Tootian Z, Javadi F. Anatomical and histological structure of the tongue and histochemical characteristics of the lingual salivary glands in the Persian squirrel (Sciurus anomalus). Anat Sci Int. 2018; 93(1): 58-68, doi: 10.1007/s12565-016-0367-5, indexed in Pubmed: 27565979.
54. Schwenk K. Morphology of the tongue in the tuatara, Sphenodon punctatus (Reptilia: Lepidosauria), with comments on function and phylogeny. J Morphol. 1986; 188(2): 129-156, doi: 10.1002/jmor.1051880202, indexed in Pubmed: 29945355.

55. Sharma R, Vidyadaran MK, Zulkifli I, et al. Ecomorphological implications of the microstructures on the tongue of the fawn roundleaf bat, Hipposideros cervinus (Chiroptera: Hipposideridae). Austr J Zool. 1999; 47(4): 405, doi: 10.1071/zo98051.

56. Son SW, Lee HJ, Lee JH. Ultrastructural observations of the lingual papillae of the Korean greater horseshoe bat, Rhinolophus ferrumequinum korai. Kyungnam Univ J Basic Sci Res Int (Korean). 2000; 14: 65-72.

57. Spicer SS, Meyer DB. Histochemical differentiation of acid mucopolysaccharides by means of combined aldehyde fuchsin-alcian blue staining. Am J Clin Pathol. 1960; 33(5_ts): 453-460, doi: 10.1093/ajcp/33.5_ts.453.

58. Suvarna SK, Layton C, Bancroft JD. Bancroft's Theory and Practice of Histological Techniques, Expert Consult: Online and Print, 7: Bancroft's Theory and Practice of Histological Techniques. Churchill Livingstone Elsevier, Churchill Livingstone 2013.

59. Tandler B, Toyoshima K, Seta Y, et al. Ultrastructure of the salivary glands in the midtongue of the common vampire bat, Desmodus rotundus. Anat Rec. 1997; 249(2): 196-205, doi: 10.1002/(SICI)1097-0185(199710)249:2<196::AIDAR6>3.0.CO;2-W, indexed in Pubmed: 9335465.

60. Wilson DE, Reeder DM. Mammal Species of the World. A Taxanomis and Geographic Reference. 2nd Ed. Smithsonium Institution Press, Washington 1993.

61. Winokur RM. The buccopharyngeal mucosa of the turtles (Testudines). J Morphol. 1988; 196(1): 33-52, doi: 10.1002/jmor.1051960105, indexed in Pubmed: 3373540.

62. Yoshimura K, Hama N, Shindo J, et al. Light and scanning electron microscopic study on the lingual papillae and their connective tissue cores of the Cape hyrax Procavia capensis. J Anat. 2008; 213(5): 573-582, doi: 10.1111/j.14697580.2008.00969.x, indexed in Pubmed: 18713236.

63. Yoshimura K, Shindoh J, Kobayashi K. Scanning electron microscopy study of the tongue and lingual papillae of the California sea lion (Zalophus californianus californianus). Anat Rec. 2002; 267(2): 146-153, doi: 10.1002/ar.10093, indexed in Pubmed: 11997883.

64. Zheng J, Kobayashi K. Comparative morphological study on the lingual papillae and their connective tissue cores (CTC) in reeves' muntjac deer (Muntiacus reevesi). Ann Anat - Anatomischer Anzeiger. 2006; 188(6): 555-564, doi: 10.1016/j. aanat.2006.05.014, indexed in Pubmed: 17140149. 